\title{
Interpretation of the SARC-F questionnaire in patients undergoing gastrointestinal cancer surgery
}

\author{
Tolga Olmez ${ }^{1}$, Can Ibrahim Bulut ${ }^{2}$, Askin Kadir Percem³, Aziz Serkan Senger ${ }^{3}$, Selcuk Gulmez ${ }^{3}$, Orhan Uzun ${ }^{3}$, \\ Erdal Polat ${ }^{3}$, Mustafa Duman ${ }^{3}$ \\ ${ }^{1}$ Department of Gastrointestinal Surgery, University of Health Sciences, Adana City Training and Research Hospital, Adana, Turkey \\ ${ }^{2}$ Department of Gastrointestinal Surgery, Balikesir City Hospital, Balikesir, Turkey \\ ${ }^{3}$ Department of Gastrointestinal Surgery, University of Health Sciences, Kartal Kosuyolu High Speciality Training and Research Hospital, Istanbul, Turkey
}

Received: 2021-02-17.

Accepted: 2021-03-13

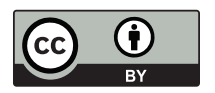

This work is licensed under a

Creative Commons Attribution 4.0 International License

J Clin Med Kaz 2021; 18(2):57-60

Corresponding author:

Tolga Olmez;

E-mail: tolgaolmez@gmail.com;

ORCID: 0000-0001-6145-6130

\section{Abstract}

Aim: Sarcopenia is a skeletal muscle disorder associated with decreased muscle mass and functional capacity. The SARC-F questionnaire facilitates sarcopenia screening in elderly patients. The present study investigates the applicability of the SARC-F questionnaire to sarcopenia screening in patients scheduled for gastrointestinal cancer surgery and its relationship with postoperative outcomes.

Material and methods: This cross-sectional study was carried out with elderly patients scheduled for gastrointestinal cancer surgery. The study included 71 patients consisting of 47 males and 24 females. The risk of sarcopenia was assessed by the Strength, Assistance with walking, Rising from a chair, Climbing stairs, and Falling (SARC-F) questionnaire. Patients with a SARC-F score $\geq 4$ were considered to be at risk of sarcopenia. The demographic data, nutritional status and comorbidity data of the patients were recorded. Statistical analysis was conducted to assess postoperative complications in those patients at risk of sarcopenia.

Results: The mean age of 71 study patients was $72.6 \pm 5.6$ years. There were 15 (21.1\%) patients with a SARC-F score $\geq 4$. The postoperative complication rate was $60 \%$ in patients with a SARC-F score $\geq 4$ in comparison with $28.5 \%$ of those with a SARC-F score $<4$, and the difference was statistically significant $(p=0.024)$. The SARC-F score $\geq 4$ group also had a longer hospital stay $(\mathrm{p}<0.001)$. Furthermore, the univariate analysis for postoperative complications revealed that SARC-F scores $\geq 4$, age $\geq 75$ years, and $\mathrm{BMI} \geq 30 \mathrm{~kg} / \mathrm{m} 2$ were statistically significant.

Conclusion: We believe that the SARC-F questionnaire has a place in sarcopenia screening in patients scheduled for gastrointestinal surgery, and it is possible to predict postoperative adverse outcomes.

Key words: SARC-F, sarcopenia, gastrointestinal cancer

\section{Introduction}

Sarcopenia is a skeletal muscle disorder associated with decreased muscle mass and functional capacity. It is common in the elderly but can also occur in young people. Its definition was made by the European Working Group on Sarcopenia in Older People 2 (EWGSOP2) [1]. Sarcopenia is called primary sarcopenia when it is age related, and secondary sarcopenia when it is caused by systemic diseases such as cancer, and organ failure. Secondary sarcopenia can occur in all age groups [2].
According to the definition by EWGSOP2 in 2018, muscle strength is the most important parameter for sarcopenia. The diagnosis of sarcopenia is confirmed by the presence of low muscle quantity or quality. Sarcopenia is considered severe with the detection of low muscle strength, low muscle quantity or quality, and poor physical performance [2].

Previous studies have shown that sarcopenia occurs in $24-45 \%$ of patients with gastrointestinal (GI) cancers and is likely to have a negative impact on length of hospital stay and complications [3-5]. Apart from the diagnostic 
methods for sarcopenia recommended by EWGSOP2, it is possible to screen elderly patients for sarcopenia using the SARC-F questionnaire developed by Malmstrom and Morley [6,7]. The SARC-F questionnaire, which is a simple method for pre-diagnosing sarcopenia, asks patients questions about 'Strength, Assistance with walking, Rising from a chair, Climbing stairs, and Falling'. The present study will investigate the applicability of the SARC-F questionnaire to sarcopenia screening in patients scheduled for GI cancer surgery and its relationship with postoperative outcomes.

\section{Materials and methods}

This cross-sectional study was carried out with patients scheduled for GI cancer surgery at the Department of Gastrointestinal Surgery of Kartal Kosuyolu Educational and Research Hospital between November 2019 and October 2020. The study was approved by the ethics committee of the study hospital (No: 2019/7/103). The study was conducted in accordance with the ethical standards specified in the Declaration of Helsinki, as revised in 2013. The inclusion criteria were being aged 65 years or older; being scheduled for elective surgery due to GI cancer; and having an Eastern Cooperative Oncology Group (ECOG) performance score of 2 or less. The exclusion criteria were having metastatic disease and being scheduled for palliative surgery. Seventy-five patients were included in the study. Two patients were excluded because of incomplete SARC-F questionnaires, and two patients because of having palliative surgery. The study continued with a total of 71 patients comprising 47 males and 24 females (Figure 1).

Figure 1 -Flow chart of the study

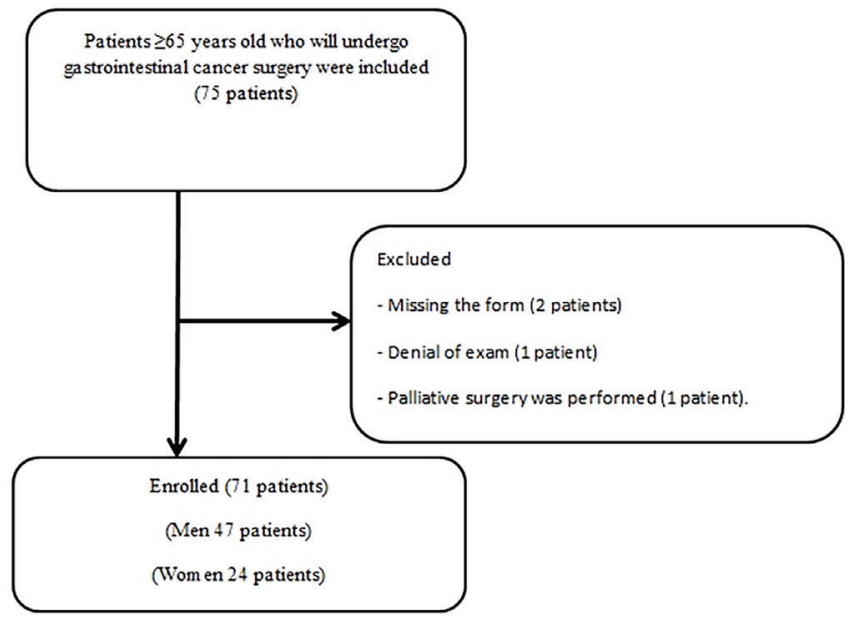

The SARC-F questionnaire was used to assess the risk of sarcopenia. Patients were asked 5 questions in this questionnaire. These questions evaluated the patients' 'strength, need for walking assistance, ability to lift a chair, ability to climb stairs and whether or not the patient has falling issues.' Each question was scored from 0 to 2 points, resulting in a total score of $0-10$ points (Table 1). Patients with a SARC-F score $\geq 4$ were considered to be at risk of sarcopenia [3,8]. Patients' demographic data including age, gender, height, weight, body mass index (BMI), smoking, history of abdominal surgery, preoperative hemoglobin levels, site of operation and name of operation were recorded. To evaluate nutritional status and comorbidity, the Nutritional Risk Screening 2002 (NRS-2002) score, Charlson Comorbidity Index (CCI), preoperative albumin levels, preoperative C-reactive protein (Crp) levels and weight

\begin{tabular}{|l|l|l|}
\hline Component & Question & Scoring \\
\hline Strength & $\begin{array}{l}\text { How much difficulty do } \\
\text { you have in lifting and } \\
\text { carrying 5 kg? }\end{array}$ & $\begin{array}{l}\text { None=0 } \\
\text { Some=1 } \\
\text { A lot or unable=2 }\end{array}$ \\
\hline Assistance in walking & $\begin{array}{l}\text { How much difficulty } \\
\text { do you have walking } \\
\text { across a room? }\end{array}$ & $\begin{array}{l}\text { None=0 } \\
\text { Some=1 } \\
\text { A lot, use aids, or } \\
\text { unable= 2 }\end{array}$ \\
\hline Rise from a chair & $\begin{array}{l}\text { How much difficulty do } \\
\text { you have transferring } \\
\text { from a chair or bed? }\end{array}$ & $\begin{array}{l}\text { None=0 } \\
\text { Some=1 } \\
\text { A lot or unable without } \\
\text { help=2 }\end{array}$ \\
\hline Climb stairs & $\begin{array}{l}\text { How much difficulty } \\
\text { do you have climbing a } \\
\text { flight of 10 stairs? }\end{array}$ & $\begin{array}{l}\text { None=0 } \\
\text { Some=1 } \\
\text { A lot or unable=2 }\end{array}$ \\
\hline Falls & $\begin{array}{l}\text { How many times have } \\
\text { you fallen in the past } \\
\text { year? }\end{array}$ & $\begin{array}{l}\text { None=0 } \\
1-3 \text { falls=1 } \\
\text { 4 falls=2 }\end{array}$ \\
\hline
\end{tabular}

Table 2

Demographic and clinical characteristics of patients.

\begin{tabular}{|c|c|c|c|c|}
\hline \multirow[t]{2}{*}{ Variables } & \multirow{2}{*}{$\begin{array}{l}\text { Total } \\
(n=71)\end{array}$} & \multicolumn{2}{|l|}{ SARC-F } & \multirow[t]{2}{*}{$\mathrm{p}$ value } \\
\hline & & $<4(\mathrm{n}=56)$ & $\geq 4(n=15)$ & \\
\hline $\begin{array}{l}\text { Age (years); } \\
\text { mean } \pm \text { SD }\end{array}$ & $72.6 \pm 5.6$ & $71.3 \pm 4.6$ & $77.6 \pm 6.2$ & 0.059 \\
\hline Gender; n(\%) & & & & 0.002 \\
\hline Male & $47(66.1)$ & $42(75)$ & $5(33.3)$ & \\
\hline Female & $24(33.9)$ & $14(25)$ & $10(66.7)$ & \\
\hline Height (cm) & $165.1 \pm 10.5$ & $166.6 \pm 10.4$ & $159.6 \pm 9.5$ & 0.84 \\
\hline Weight (cm) & $77 \pm 15.1$ & $74.8 \pm 14.1$ & $85 \pm 16.8$ & 0.48 \\
\hline $\begin{array}{l}\mathrm{BMI}(\mathrm{kg} / \mathrm{m} 2) \\
\text { mean } \pm \mathrm{SD}\end{array}$ & $28.4 \pm 5.2$ & $27.1 \pm 4.2$ & $33.3 \pm 5.5$ & $<0.001$ \\
\hline Smoker; n(\%) & $10(14)$ & $8(14.2)$ & $2(13.3)$ & 0.92 \\
\hline $\begin{array}{l}\text { Abdominal } \\
\text { operation history; } \\
\mathrm{n}(\%)\end{array}$ & $14(19.7)$ & $10(17.8)$ & $4(26.6)$ & 0.44 \\
\hline $\begin{array}{l}\text { NRS-2002 } \\
\text { score(\%) }\end{array}$ & & & & 0.49 \\
\hline $0-1$ & $34(47.8)$ & $28(50)$ & $6(40)$ & \\
\hline$\geq 2$ & $37(52.2)$ & $28(50)$ & $9(60)$ & \\
\hline $\operatorname{CCI}(\%)$ & & & & 0.25 \\
\hline $0-1$ & 51 (71.8) & $42(75)$ & $9(60)$ & \\
\hline$\geq 2$ & $20(28.2)$ & $14(25)$ & $6(40)$ & \\
\hline $\begin{array}{l}\text { Preoperative } \\
\text { hemoglobulin(g/ } \\
\mathrm{dL}) \text {; mean } \pm \text { SD }\end{array}$ & $11.4 \pm 1.7$ & $11.6 \pm 1.7$ & $10.6 \pm 1.7$ & 0.99 \\
\hline $\begin{array}{l}\text { Preoperative } \\
\text { albumin }(\mathrm{g} / \mathrm{L}) ; \\
\text { mean } \pm \mathrm{SD}\end{array}$ & $3.8 \pm 0.3$ & $3.8 \pm 0.3$ & $3.7 \pm 0.2$ & 0.031 \\
\hline $\begin{array}{l}\text { Preoperative } \\
\text { C-reactive } \\
\text { protein }(\mathrm{mg} / \mathrm{L}) ; \\
\text { mean } \pm \mathrm{SD}\end{array}$ & $4.8 \pm 2.9$ & $5.8 \pm 3.5$ & $4.5 \pm 2.6$ & 0.012 \\
\hline Weight loss*; n(\%) & $10(14)$ & $10(17.8)$ & 0 & 0.74 \\
\hline $\begin{array}{l}\text { SARC-F score; } \\
\text { mean } \pm \text { SD }\end{array}$ & $2 \pm 1.6$ & $1.3 \pm 1$ & $4.5 \pm 0.7$ & 0.05 \\
\hline
\end{tabular}

Values are presented as mean \pm SD (standard deviation) or $\mathrm{n}(\%)$. Preoperative BMI body mass index, CCI Charlson comorbidity index, NRS2002 Nutritional Risk Screening-2002 are presented.

*Expresses more than $10 \%$ weight loss in the last 3 months. 


\begin{tabular}{|l|l|l|l|l|}
\hline Variables & & SARC-F & & $\geq 4(\mathrm{n}=15)$ \\
\hline & Total $(\mathrm{n}=71)$ & $<4(\mathrm{n}=56)$ & & $\mathrm{p}$ value \\
\hline Primary diagnosis; $\mathrm{n}(\%)$ & & & 0.06 \\
\hline Colon & $32(45)$ & $26(46.4)$ & $6(40)$ & \\
\hline Rectum & $17(23.9)$ & $12(21.4)$ & $5(33.3)$ & \\
\hline Gastric & $12(16.9)$ & $10(17.8)$ & $2(13.3)$ & 0 \\
\hline Pancreas & $2(2.8)$ & $2(3.5)$ & 0 & \\
\hline Intraabdominal mass & $6(8.4)$ & $6(10.5)$ & $2(13.3)$ & \\
\hline Others & $12(2.8)$ & 0 & & 0.11 \\
\hline Operation type; $\mathrm{n}(\%)$ & & & $2(13.3)$ & \\
\hline Anterior resection & $16(22.5)$ & $14(25)$ & $5(33.3)$ & \\
\hline Low anterior resection+loop ileostomy & $15(21.1)$ & $10(17.8)$ & $2(13.3)$ & \\
\hline Right hemicolectomy & $12(16.9)$ & $10(17.8)$ & 0 & \\
\hline Left hemicolectomy & $2(2.8)$ & $2(3.5)$ & $2(13.3)$ & \\
\hline Transvers colectomy & $2(2.8)$ & 0 & 0 & \\
\hline Subtotal colectomy & $2(2.8)$ & $2(3.5)$ & $2(13.3)$ & \\
\hline Total gastrectomy & $4(5.6)$ & $2(3.5)$ & 0 & \\
\hline Subtotal gastrectomy & $8(11.2)$ & $8(14.2)$ & 0 & \\
\hline Pancreatectomy & $2(2.8)$ & $2(3.5)$ & 0 & \\
\hline Small bowel resection & $2(2.8)$ & $2(3.5)$ & $2(13.3)$ & \\
\hline Others & $6(8.4)$ & $4(7.1)$ & $9(60)$ & \\
\hline Postoperative complication; $\mathrm{n}(\%)$ & $25(35.2)$ & $16(28.5)$ & $16.4 \pm 11.9$ & 0.024 \\
\hline Lenght of hospital stay; mean \pm SD & $11.3 \pm 6.9$ & $9.9 \pm 4.0$ & $<0.001$ \\
\hline & & & \\
\hline
\end{tabular}

loss in the previous 3 months were recorded. Finally, the effect of the SARC-F scores on postoperative complications and length of hospital stay was examined.

\section{Statistical analysis}

Categorical variables were presented as number and percentage. Normally distributed continuous variables were presented as mean and standard deviation (SD). Clinical variables were assessed using Student's t-test and Pearson's Chi-square test. Factors with an impact on postoperative complications were assessed using regression analysis. A p value of $<0.05$ was considered statistically significant for all tests, and all statistical analyses were conducted using SPSS Statistics, Version 25.0 (IBM, Armonk, NY).

\section{Results}

The mean age of 71 study patients was $72.6 \pm 5.6$ years. The mean age of $15(21.1 \%)$ patients with a SARC-F score $\geq 4$ was $77.6 \pm 6.2$ years, while the mean age of $56(78.9 \%)$ patients with a SARC-F score $<4$ was $71.3 \pm 4.6$ years $(p=0.059)$. The number of women was significantly higher in the patient group with a SARC-F score $\geq 4(66.7 \%$ vs $33.3 \%, \mathrm{p}=0.002)$. The mean BMI was $33.3 \pm 5.5 \mathrm{~kg} / \mathrm{m} 2$ in the SARC-F score $\geq 4$ group in comparison with $27.1 \pm 4.2 \mathrm{~kg} / \mathrm{m} 2$ in the SARC-F score $<4$ group $(\mathrm{p}<0.001)$. Regarding nutritional status, the distribution of the NRS-2002 score $\geq 2$ was similar between groups ( $p=0.49$ ), while preoperative albumin and Crp levels were significantly lower in the SARC-F score $\geq 4$ group (albumin: $3.8 \mathrm{~g} / 1$ vs. 3.7 $\mathrm{g} / \mathrm{l}, \mathrm{p}=0.031$; Crp: $5.8 \mathrm{mg} / \mathrm{l}$ vs. $4.5 \mathrm{mg} / \mathrm{l}, \mathrm{p}=0.012$ ). Patients' demographic data and clinical variables are presented in Table 2.

All patients underwent surgery due to gastrointestinal cancers in accordance with oncological surgical principles. Cancer types and surgery types are presented in Table 3. The postoperative complication rate was higher in the SARC-F score $\geq 4$ group ( $60 \%$ vs. $28.5 \%, p=0.024)$. The length of hospital stay was also longer in the SARC-F score $\geq 4$ group (9.9 \pm 4.0 days vs. $16.4 \pm 11.9$ days, $p<0.001)$. When the types of complication were examined, the most common complication was surgical site infection in both groups (10/16 patients in the SARC-F score $<4$ group; $4 / 16$ patients in the SARC-F score $\geq 4$ group). Anastomotic leak did not occur in the SARC-F score $<4$ group, while it was detected in 3 patients in the SARC-F score $\geq 4$ group. Details on complications are presented in Table 4.

The univariate analysis for postoperative complications revealed that SARC-F scores $\geq 4$ (OR $=0.267,95 \%$ CI: 0.082 $0.872, \mathrm{p}=0.029)$, age $\geq 75$ years $(\mathrm{OR}=0.301,95 \% \mathrm{CI}: 0.105$ $0.862, \mathrm{p}=0.025)$, and $\mathrm{BMI} \geq 30 \mathrm{~kg} / \mathrm{m} 2(\mathrm{OR}=0.344,95 \% \mathrm{CI}$ : $0.125-0.943, \mathrm{p}=0.038$ ) were statistically significant (Table 5).

Table 4 Types of postoperative complications.

\begin{tabular}{|l|l|l|}
\hline Postoperative complications & SARC-F $<4(n=16)$ & SARC-F $\geq 4(n=9)$ \\
\hline Surgical site infection & 10 & 4 \\
\hline Anastomotic leakage & 0 & 3 \\
\hline Bleeding & 2 & 2 \\
\hline Pneumonia & 2 & 0 \\
\hline İleus & 2 & 0 \\
\hline
\end{tabular}

Table 5

Univariate analysis for postoperative complications

\begin{tabular}{|l|l|l|l|}
\hline & OR & $(95 \% \mathrm{CI})$ & P value \\
\hline SARC-F $(\geq 4 /<4)$ & 0.267 & $0.082-0.872$ & 0.029 \\
\hline $\begin{array}{l}\text { Age }(\geq 75 /<75 \\
\text { years })\end{array}$ & 0.301 & $0.105-0.862$ & 0.025 \\
\hline $\begin{array}{l}\mathrm{BMI}(\geq 30 /<30 \\
\mathrm{kg} / \mathrm{m} 2)\end{array}$ & 0.344 & $0.125-0.943$ & 0.038 \\
\hline
\end{tabular}

\section{Discussion}

The results of the present study revealed that $21.1 \%$ of the patients had a SARC-F score $\geq 4$, suggesting that these patients were at risk of sarcopenia. Furthermore, this patient group had a higher rate of complications following gastrointestinal cancer surgery and had a significantly prolonged hospital stay. In other words, SARC-F scores $\geq 4$ were found to result in adverse postoperative outcomes in elderly patients. 
There are several recent studies regarding the usability of the SARC-F questionnaire in sarcopenia screening. Among them is the study by HA et al. on sarcopenia screening in elderly patients with hip fractures [9]. The study included 115 patients and concluded that the SARC-F questionnaire could be used in sarcopenia screening in elderly patients with hip fractures.

Another cross-sectional study found that $40 \%$ of 77 patients diagnosed with gastrointestinal cancer had a SARC-F score $\geq 4$ and were at risk of sarcopenia [10]. The same study further established that sarcopenia risk was associated with Charlson comorbidity index and NRS-2002 score. This study also included young individuals, which is the most important difference from the present study. In this study we included only elderly patients. Thus, using the SARC-F questionnaire, we calculated the total risk including both the risk of secondary sarcopenia due to cancer and the risk of primary sarcopenia associated with age.

Another study by Soares et al. established SARC-F scores $\geq 4$ in $25.4 \%$ of 71 patients with gastrointestinal cancer, which was associated with increased anxiety [8]. The same study found a lower mean BMI in the SARC-F score $\geq$ 4group. In the present study, however, the mean BMI was statistically significantly higher in the group with sarcopenia risk. We believe this could be due to sarcopenic obesity.

Another study established a sarcopenia risk of $17 \%$ based on the SARC-F questionnaire [11]. According to the literature data, the risk of sarcopenia based on the SARC-F questionnaire increases up to $40 \%$. The present study found a sarcopenia risk of $21.1 \%$, which is consistent with the literature. The wide range of sarcopenia risk may be because the patient groups in some studies are not homogeneous, and when compared with other studies, there are for example significant differences in patient selection.

The SARC-F questionnaire does not diagnose sarcopenia but determines the patient's risk of sarcopenia. Our aim was to demonstrate the applicability of this questionnaire to patients scheduled for gastrointestinal cancer surgery and no such research had been conducted until the commencement of the present study. Recent studies have focused on patients with sarcopenia diagnosed using various methods. According to a recently published meta-analysis, sarcopenia is associated with poor postoperative outcomes and decreased survival rates in colorectal cancer patients [12]. Supporting the meta-analysis, our study established a higher rate of postoperative complications and a longer hospital stay in patients with a SARC-F score $\geq 4$. Major complications, such as anastomotic leak, were detected in the patient group with sarcopenia risk.

The present study has a number of limitations. First, this was a single-center study. Secondly, the study included a relatively small patient group. Although this is the first sarcopenia screening study in elderly patients scheduled for gastrointestinal cancer surgery, the cancer was not specific to organ, which was another limitation of the study.

\section{Conclusion}

In conclusion, we believe that the SARC-F questionnaire has a place in sarcopenia screening in patients scheduled for gastrointestinal cancer surgery, and it is able to predict postoperative adverse outcomes.

Disclosures: There is no conflict of interest for all authors.

\section{References}

1. Cruz-Jentoft AJ, Bahat G, Bauer J, Boirie Y, Bruyere O, Cederholm T et al. Sarcopenia: revised European consensus on definition and diagnosis. Age Ageing. 2019; 48(1):16-31. https://doi.org/10.1093/ageing/afz046

2. Cruz-Jentoft AJ, Baeyens JP, Bauer JM, Boirie Y, Cederholm T, Landi F et al. Sarcopenia: European consensus on definition and diagnosis: report of the European working group on sarcopenia in older people. Age Ageing. 2010; 39:412-23. https://doi.org/10.1093/ ageing/afq034

3. Barbosa-Silva TG, Menezes AMB, Bielemann RM, Malmstrom TK, Gonzalez MC; Grupo de Estudos em Composição Corporal e Nutrição (COCONUT). Enhancing SARC-F: Improving Sarcopenia Screening in the Clinical Practice. J Am Med Dir Assoc. 2016; 17(2):1136-41. https://doi.org/10.1016/j.jamda.2016.08.004

4. Olmez T, Karakose E, Bozkurt H, Pence H, Gulmez S, Aray E et al. Sarcopenia is associated with increased severe postoperative complications after colon cancer surgery. Arch Med Sci. Accepted article: Sept 12, 2019. Published Online: Oct 09, 2019. https://doi. org/10.5114/aoms.2019.88621

5. Vashi PG, Gorsuch K, Wan L, Hill D, Block C, Gupta D. Sarcopenia supersedes subjective global assessment as a predictor of survival in colorectal cancer. PLoS One. 2019; 14(6):1-14. https://doi.org/10.1371/journal.pone.0218761

6. Malmstrom TK, Morley JE. SARC-F: a simple questionnaire to rapidly diagnose sarcopenia. J Am Med Dir Assoc. 2013; 14:531-2. https://doi.org/10.1016/j.jamda.2013.05.018

7. Malmstrom TK, Miller DK, Simonsick EM, Ferrucci L MJ. SARC-F: a symptom score to predict persons with sarcopenia at risk for poor functional outcomes. J Cachexia Sarcopenia Muscle. 2016; 7:28-36. https://doi.org/10.1002/jcsm.12048

8. Soares JDP, Gomes TLN, Siqueira JM, Oliveira ICL, Mota JF, Laviano A et al. Muscle function loss is associated with anxiety in patients with gastrointestinal cancer. Clin Nutr ESPEN. 2019; 29:149-53. https://doi.org/10.1016/j.clnesp.2018.11.003

9. Ha Y-C, Won Won C, Kim M, Chun K-J, Yoo J-I. SARC-F as a Useful Tool for Screening Sarcopenia in Elderly Patients with Hip Fractures. J Nutr Heal Aging. 2020; 24(1):78-82. https://doi.org/10.1007/s12603-019-1307-6

10. Borges TC, Gomes TLN, Pimentel GD. Sarcopenia as a predictor of nutritional status and comorbidities in hospitalized patients with cancer: A cross-sectional study. Nutrition. 2020; 73:110703. https://doi.org/10.1016/j.nut.2019.110703

11. Rolland Y, Dupuy C, Abellan Van Kan G, Cesari M, Vellas B, Faruch M et al. Sarcopenia Screened by the SARC-F Questionnaire and Physical Performances of Elderly Women: A Cross-Sectional Study. J Am Med Dir Assoc. 2017; 18(10):848-52. https://doi. org/10.1016/j.jamda.2017.05.010

12. Trejo-Avila M, Bozada-Gutiérrez K, Valenzuela-Salazar C, Herrera-Esquivel J, Moreno-Portillo M. Sarcopenia predicts worse postoperative outcomes and decreased survival rates in patients with colorectal cancer: a systematic review and meta-analysis. Int $\mathrm{J}$ Color Dis. Accepted Article: Jan 8, 2021. Published online: Jan 22,2021. https://doi.org/10.1007/s00384-021-03839-4 